\title{
Keamanan Aplikasi Web Melalui Penerapan Cross Site Request Forgery(CSRF)
}

\author{
Taufik R. Firdaus \\ Jurusan Teknik Informatika \\ STMIK IKMI Cirebon
}

\begin{abstract}
Absract
Currently the Internet became one of the media that can not be separated, as well as a wide variety of applications supplied her. As the development of technologies, reliance on Web applications also increased. However, web applications have a wide range of threats, one of it is a CSRF (Cross-Site Request Forgery). This study uses CSRF (Cross-Site Request Forgery) Protection. CSRF (Cross-Site Request Forgery) Protection is a treatment method that has a variety of ways, one of which uses a token in the session when the user login. Token generated at login will be used as a user id that the system of web applications to identify where the request originated. The results of this study are expected in order to increase web application defenses against CSRF (Cross-Site Request Forgery), so that web application users will be able to feel safe in using the Internet and its various feature. Reduced level of attacks on web applications. So that visitor traffic on the web application can be increased.
\end{abstract}

Keyword : CSRF(Cross-Site Request Forgery), Web Application, Request, Token, Security.

\section{Latar Belakang}

Aplikasi web merupakan platform perangkat lunak terbaru yang dominan pada saat ini, dikembangkan setiap harinya demi memudahkan kinerja manusia dalam menyelesaikan pekerjaan. Akan tetapi semakin banyak aplikasi web bertambah pula kerentanan keamanan aplikasi web yang dapat merugikan penggunanya. Kerugian yang dapat dialami pengguna seperti halnya berupa kehilangan data pribadi, rahasia dan finansial. Maka dari itu dibutuhkan lah teknik pengamanan yang dapat melindungi data pengguna dari kerentanan keamanan yang ada pada aplikasi web.

Serangan cross site request forgery(CSRF) merupakan ancaman aplikasi web yang ditunjukkan untuk mencuri informasi pengguna aplikasi web. Menurut penelitian yang dilakukan oleh Rupali D. Kombade dan Dr. B.B. Meshram dalam penelitiannya yang berjudul "CSRF Vulnerabilities and Defensive Techniques" mengatakan bahwa:

"CSRF(Cross-Site Request Forgery) merupakan sebuah serangan yang mana memaksa pengguna untuk mengeksekusi aksi yang tidak di inginkan pada aplikasi web, dimana dia 
(korban) saat ini terautentikasi. Serangan ini memanfaatkan keuntungan fungsi protokol HTTP untuk mengirim session cookie pada saat request ke server setiap kali pengguna berhasil melakukan autentikasi, yang membantu server dalam memastikan request tersebut berasal dari pengguna otentik.”(Kombade \& Meshram, 2012, p. 31)

Aplikasi web merupakan aplikasi yang memanfaatkan teknologi web dan web browser untuk menyelesaikan satu tugas atau lebih pada jaringan khususnya pada sebuah web browser. Menurut jurnal yang ditulis oleh Rupali D. Kombade dan Dr. B.B Meshram yang berjudul “CSRF Vulnerabilities and Defensive Techniques", dikatakan bahwa:

"Aplikasi web menjadi bagian dari kehidupan manusia. Beberapa diantaranya mengurangi usaha mereka seperti (sistem pemesanan, perbankan online, dll) dan beberapa diantaranya menghibur dan menghubungkan mereka secara social (facebook, myspace, dll). Akan tetapi dengan semua fasilitas ini mereka juga membawa beberapa masalah seperti hal nya serangan aplikasi web.”(Kombade \& Meshram, 2012)

Penelitian yang ditulis oleh Rupali D. Kombade dan Dr. B.B Meshram yang berjudul "CSRF Vulnerabilities and Defensive Techniques" yang dimuat dalam jurnal tahun 2012 serangan ini sedikit sekali diketahui oleh developers, beberapa menganggap ini sama seperti dengan XSS dan beberapa diantaranya menganggap ini teknik mitigasi XSS akan bekerja pada serangan ini. Tetapi ini berbeda dari XSS dan teknik mitigasi membutuhkan sesuatu usaha tambahan dibandingkan dengan langkah - langkah pertahanan XSS. Serangan CSRF telah diketahui sebagai "raksasa yang tertidur(sleeping giant)" pada celah keamanan berbasis web, karena banyak situs di internet gagal melindungi dari mereka dan mereka telah dihiraukan oleh web developmer dan komunitas keamanan.(Kombade \& Meshram, 2012)

Pada penelitian lain yang dilakukan oleh Adam Barth, Collin Jackson, dan John Mitcheil pada jurnal tahun 2013 tentang “Robust Defenses for Cross Site Request Forgery” pertahanan CSRF yang paling populer adalah dengan menambahkan token rahasia pada setiap request dan untuk validasi itu token yang diterima terikat dengan tepat pada sesi pengguna, mencegah CSRF dengan memaksa penyerang untuk menebak sesi token. Ada sejumlah variasi terhadap pendekatan ini, masing - masing penuh dengan jebakan, dan bahkan situs yang mengimplementasikan teknik ini dengan benar seringkali mengabaikan login requests mereka karena login requests kekurangan sesi untuk mengikat token.(Barth, Jackson, \& Mitchell, 2008, pp. 75-76) 
Dari penelitian diatas dapat disimpulkan bahwa untuk mengatasi serangan cross site request forgery dapat dilakukan melalui cara menambahkan token rahasia yang mengikat sesi pengguna dengan token.

Penelitian tentang celah keamanan cross site request forgery yang telah dilakukan oleh Rupali D. Kombade dan Dr. B.B. Meshram tentang "CSRF Vulnerabilities and Defensive Techniques" masalah yang diankat pada jurnal ini bahwa aplikasi perangkat lunak CSRF guard dan CSRF detector merupakan perangkat yang sangat kuat akan tetapi masih belum dapat memberikan proteksi penuh, mereka hanya dapat mengurangi serangan CSRF. Oleh karena itu pertahanan menyeluruh terhadap serangan CSRF tidak tersedia.(Kombade \& Meshram, 2012) Pada penelitian yang dilakukan oleh Ramisetty Ramaro yang dimuat pada tesisnya pada tahun 2009 yang berjudul "Heuristics for Preventing Cross Site Request Forgery" dengan mengangkat masalah bahwa mekanisme validasi token rahasia merupakan salah satu mekanisme yang efisien untuk mencegah serangan CSRF. SERIDE (SEssion RIding DEfender) merupakan open source php library yang menggunakan mekanisme validasi token rahasia untuk mencegah serangan CSRF dengan sukses pada sisi server di setiap php aplikasi web. Dalam proyek ini, kita mengembangkan sebuah alat open source SASERIDE yang mana merupakan alat semi otomatis dan pengembangan kode program SERIDE yang telah ada.(Ramarao, 2009, p. 82) Dari penelitian yang telah dilakukan tersebut di atas disimpulkan bahwa penggunaan token dalam mengamankan aplikasi web merupakan pilihan yang tepat untuk mengatasi serangan cross site request forgery dimana token akan di enkripsi terlebih dahulu agar penyerang tidak dapat mengira apa isi token tersebut.

\section{Permasalahan}

Berdasarkan latar belakang masalah diatas, maka rumusan masalah dalam penelitian ini, adalah :

a. Kurangnya kesadaran pengembang aplikasi web terhadap Cross Site Request Forgery(CSRF)

b. Semakin banyaknya situs yang tidak dipercaya sehingga kemungkinan pencurian data bertambah

c. Semakin banyaknya aplikasi web yang dibuat setiap tahunnya 
Selanjutnya terkait dengan masalah tersebut di atas penulis merumuskannya ke dalam bagan di bawah ini:

\section{FAKTOR DETERMINAN}

Peningkatan jumlah pengguna, peningkatan pertumbuhan aplikasi web sehingga semakin banyak web jahat yang ada di internet saat ini. Disisi lain upaya perbaikan celah masih kurang karenya minimnya pengetahuan akan keamanan aplikasi web yang dimiliki oleh pengembang dan administrator yang dapat menyebabkan banyak pengguna yang dirugikan.

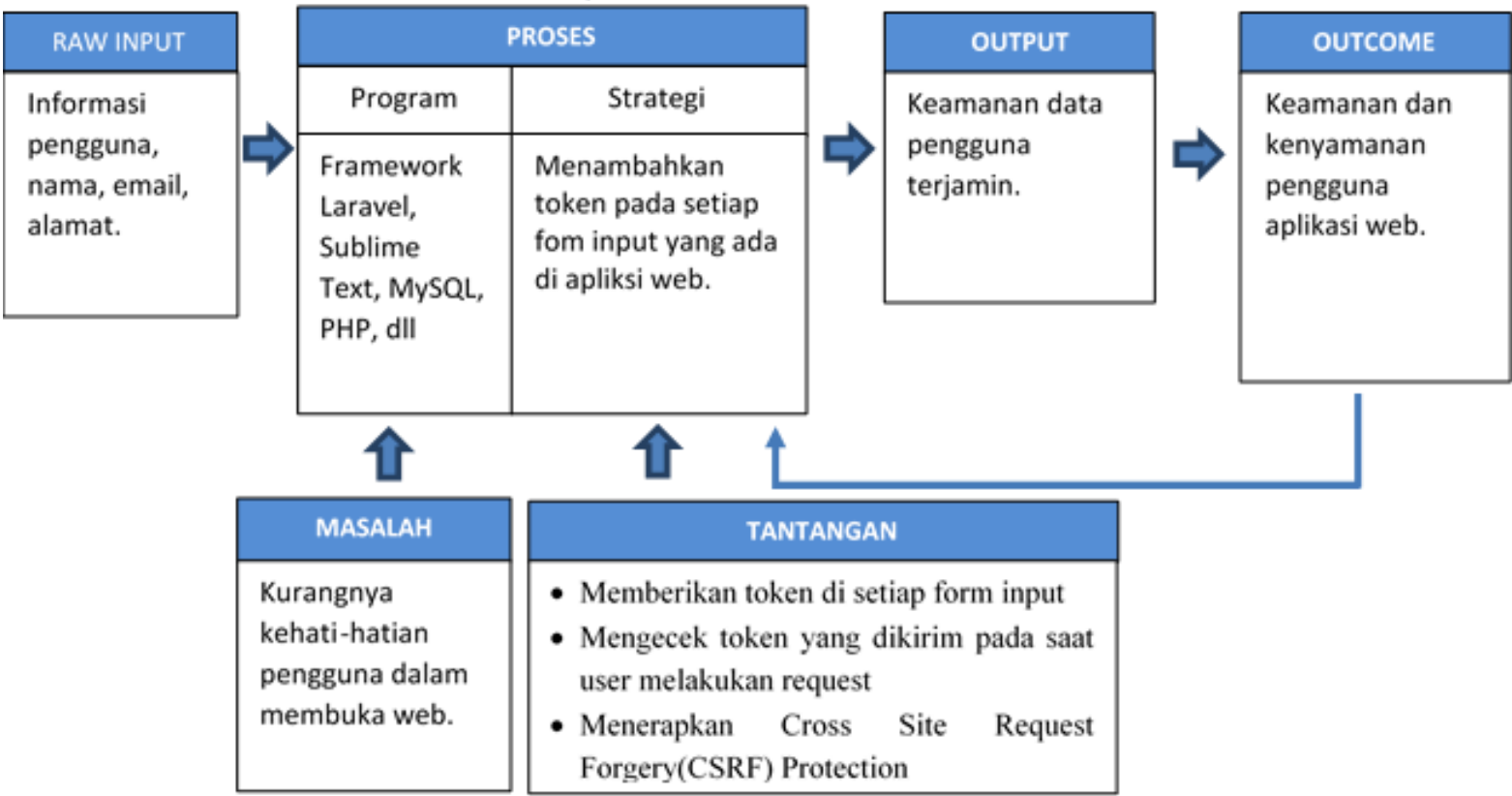

Gambar 1 : Rumusan Masalah

\section{Landasan Teori}

\section{Web Server}

Apa yang memulai server sederhana yang memproses HTTP request biasa berubah menjadi server besar multithread yang mampu melayani ribuan request. Semakin permintaan berkembang begitu juga halnya pada jumlah webserver.

Web server mulai menyediakan semakin banyak fitur. Semakin berkembangnya permintaan, keinginan orang untuk melakukan transaksi menggunakan media ini juga bertambah. Web server menjadi bahan utama pada fungsi ini yang dapat membantu mengendalikan beberapa keadaan.(Wells, 2007, p. 17) 


\section{Aplikasi Web}

Berdasarkan definisi, itu sesuatu yang lebih dari sekedar "situs web". Itu adalah aplikasi klien/server yang menggunakan web browser sebagai program klien nya, dan melakukan pelayanan interaktif dengan menghubungkannya bersama server melalui internet (atau intranet). Sebuah website hanya mengirimkan kontent simple yang berasal dari file statik. Aplikasi web menyediakan konten dinamis yang disesuaikan berdasarkan parameter, tingkah laku pengguna, dan pertimbangan keamanan.(Shklar \& Rosen, 2003, p. 5)

\section{Kriptografi}

Menurut Fresly Nandar Pabokory, Indah Fitri Astuti, Awang Harsa Kridalaksana dalam jurnalnya pada tahun 2015 dengan judul Implementasi Kriptografi Pengamanan Data Pada Pesan Teks, Isi File Dokumen, Dan File Dokumen Menggunakan Algoritma Advanced Encryption kriptografi merupakan seni dan ilmu untuk memproteksi pengiriman data dengan mengubahnya menjadi kode tertentu dan hanya ditujukan untuk orang yang hanya memiliki sebuah kunci untuk mengubah kode itu kembali yang berfungsi dalam menjaga kerahasiaan data atau pesan. Dalam kriptografi, data atau pesan yang dikirimkan melalui jaringan akan disamarkan sedemikian rupa sehingga tidak dapat diketahui isi dan arti dari pesan tersebut. Dalam bidang kriptografi terdapat dua konsep yang sangat penting atau utama yaitu:

\section{A. Enkripsi}

Enkripsi merupakan proses dimana informasi atau data yang hendak dikirimkan diubah menjadi bentuk yang hampir tidak dikenali sebagai informasi awalnya dengan menggunakan algoritma tertentu.

\section{B. Dekripsi}

Dekripsi adalah kebalikan dari enkripsi yaitu mengubah kembali bentuk tersamar tersebut menjadi informasi awal.

Sebuah pesan atau data yang masih asli dan belum mengalami penyandian dikenal dengan istilah plaintext. Kemudian setelah disamarkan dengan suatu cara penyandian, maka plaintext ini disebut sebagai chipertext. Proses penyamaran dari plaintext ke ciphertext disebut enkripsi (encryption), dan proses pengembalian dari ciphertext menjadi plaintext kembali disebut dekripsi (decryption).

\section{Keamanan Aplikasi Web}

Seperti halnya kelas teknologi terbaru, aplikasi web telah membawa jarak kerentanan keamanan terbaru. Kumpulan yang paling sering ditemui cacat telah berkembang seiring nya waktu. Serangan terbaru yang telah telah tercipta tidak di pertimbangkan pada saat aplikasi 
dibuat. Berbagai masalah terlah menjadi umum sebagaimana telah bertambahnya kesadaran mereka. Teknologi baru yang telah dikembangkan mengenalkan kemungkinan terbaru untuk di eksploitasi. Beberapa kategori kelemahan sebagian besar telah mengilang sebagai hasil dari perubahan yang dibuat pada perangkat lunak web browser.

Serangan yang paling serius pada aplikasi web adalah mereka yang membongkar data sensitif atau mendapatkan hak akses yang memperbolehkan mengakses ke backend sistem dimana tempat aplikasi berjalan. Kompromi profil tingkat tinggi semacam ini sering terjadi saat ini. Untuk banyak organisasi, bagaimana pun juga, apapun serangan yang menyebabkan berhentinya sistem adalah kejadian yang kritis. Aplikasi setingkat serangan denial of service(dos) dapat digunakan untuk memperoleh hasil yang sama dengan habis nya sumber daya pada serangan terhadap infrastruktur. Akan tetapi mereka juga sering digunakan dengan teknik dan tujuan yang lebih halus. Mereka mungkin digunakan untuk mengganggu pengguna atau layanan tertentu untuk mendapatkan akhir dari kompetisi dengan pesaing pada dunia pertukaran finansial, permainan, judi online, dan pemesanan tiket.

Melalui evolusi ini, kompromi pada aplikasi web terkemuka masih tetap pada berada pada berita. Disini tidak terasa bahwa sudut akan berubah dan permasalahan keamanan ini berkurang. Oleh beberapa ukuran, keamanan aplikasi web saat ini menjadi sebagian besar medan perang antara penyerang dan mereka yang bersama sumberdaya komputer dan data untuk di pertahankan, dan ini sepertinya akan terus berlangsung pada masa depan yang telah terduga.(Stuttard \& Pinto, 2011, p. 6)

\section{Cross Site Request Forgery(CSRF)}

Pada serangan cross site request forgery, penyerang mengganggu integritas sesi pengguna dengan website melalui memasukkan network request lewat browser pengguna. Peraturan keamanan browser memperbolehkan website untuk mengirimkan HTTP requests kepada setiap alamat jaringan. Peraturan ini memperbolehkan penyerang untuk mengontrol content yang ditampilkan oleh browser untuk menggunakan resource yang tidak dinyatakan dibawah kekuasaannya(penyerang):

a. Network Connectivity(Konektivitas Jaringan)

Sebagai contoh, jika seorang pengguna berada dibalik firewall, penyerang dapat mempengaruhi browser pengguna untuk mengirimkan network requests kepada mesin dibalik firewall yang mungkin tidak secara langsung berada dalam batas jangkauan mesin penyerang. Walau pun pengguna tidak berada dibalik firewall, request membawa 
alamat IP pengguna dan kemungkinan membingungkan layanan yang menggunakan autentikasi alamat IP.

b. Read Browser State(Membaca Kondisi Browser)

Request dikirim melalui tumpukan jaringan browser biasanya menyertakan keadaan browser, seperti halnya cookie, sertifikat klien, atau headers autentikasi dasar. Situs yang mengandalkan kondisi autentikasi seperti ini kemungkinan akan di pusingkan dengan requests semacam ini.

c. Write Browser State(Menulis Kondisi Browser)

Ketika penyerang menyebabkan permasalahan network request pada browser, browser juga menguraikan dan bertindak pada respon. Seperti contoh, jika respon mengandung sebuah Set-Cookie header, sebuah browser akan memodifikasi cookie yang disimpannya. Modifikasi ini dapat mengawali serangan yang mulus(lancar), seperti gambar berikut:

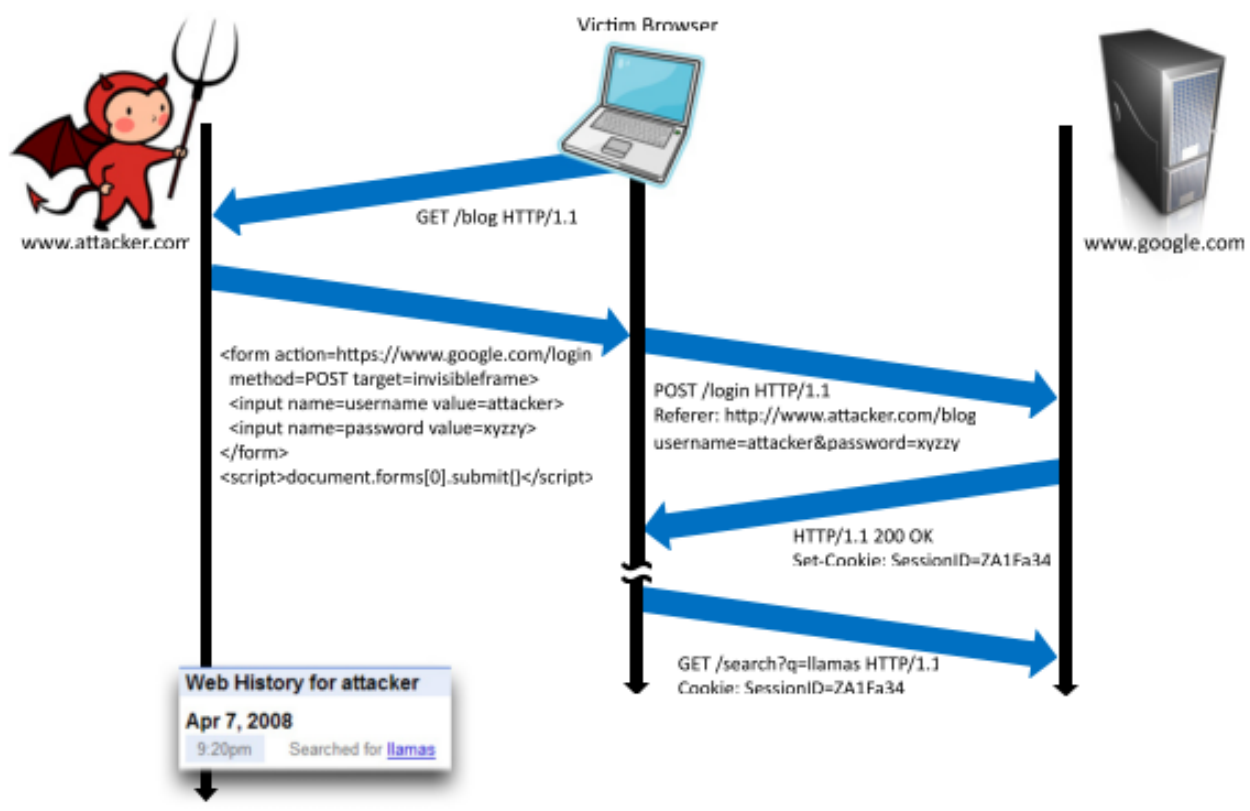

Gambar 2 : Contoh serangan CSRF dengan memodifikasi cookie

Ancaman yang berada di dalam lingkup atau ruang. Kami mempertimbangkan tiga model ancaman yang berbeda, bervariasi dengan kemampuan penyerang:

a. Forum Poster

Banyak website, seperti forum, membiarkan pengguna untuk memberikan konten yang terbatas. Sebagai contoh, situs seringkali memperbolehkan pengguna untuk 
meyerahkan konten pasif, seperti gambar atau hyperlinks. Jika penyerang memilih URL gambar jahat, kemungkinan network request mengarah kepada serangan CSRF.

b. Web Attacker

Sebuah web penyerang adalah pelaku utama berbahaya yang memiliki nama domain, sertifikat SSL yang resmi, dan beroperasi pada web server. Semua kemampuan ini dapat diperoleh hanya dengan \$10USD. Jika pengguna mengunjungi attacker.com, seorang penyerang dapat menempelkan sebuah serangan CSRF dengan menginstruksikan browser pengguna untuk melakukan cross-site requests menggunakan kedua metode GET dan POST.

c. Network Attacker

Sebuah jaringan penyerang adalah pelaku utama berbahaya yang mengontrol koneksi jaringan pengguna. Seperti contoh, sebuah "evil twin" wireless router atau server DNS yang terambil alih dapat di manfaatkan oleh penyerang untuk mengendalikan koneksi jaringan pengguna. Serangan ini membutuhkan lebih banyak sumber daya dari pada serangan web, tetapi kita mempertimbangkan ancaman ini dalam lingkup situs HTTPS karena HTTPS dirancang untuk melindungi dari serangan jaringan yang aktif.

Keluar dari ruang lingkup ancaman. Ada sejumlah model ancaman yang terkait yang tidak dipertimbangkan. CSRF defenses dan protection merupakan pertahanan yang saling mengisi dari ancaman berikut ini:
a. Cross Site Scripting(XSS)
b. Malware
c. DNS Rebinding
d. Certificate Errors
e. Phishing
f. User Tracking(Barth et al., 2008, p. 76-77)

\section{Laravel Framework}

Menurut buku yang ditulis oleh Jack Vo yang berjudul Learning Laravel: The Easiest Way Laravel adalah full stack framework, yang artinya anda dapat mengembangkan aplikasi web secara komplit dari awal menggunakan warper database menakjubkan yang disebut Eloquent ORM dan mesin template dengan nama Blade. Banyak permasalahan dalam proses pembuatan aplikasi web yang sudah diselesaikan oleh Laravel.

"Syntax dari Laravel sangatlah bersih dan mudah di ikuti. Metode dan fungsi di definisikan dengan baik. Terkadang anda dapat mengiranya tanpa melihat ke dokumentasi. Anda juga 
dapat membuat peraturan sendiri, gaya anda untuk menulis kode. Laravel juga memberikan bayak kebebasan lainnya.”(Vo, 2014, p. 6)

\section{Metode Analisis GAP}

Menurut buku yang ditulis oleh K. Douglas Hoffman dan Johtn E.G. Bateson yang berjudul Services Marketing Concept, Strategies, \& Cases Gap analysis adalah suatu alat yang digunakan untuk mengetahui mengenai kondisi aktual yang sedang berjalan di perusahaan tersebut, untuk kemudian diperbandingkan dengan sumber daya perusahaan tersebut. Hal tersebut dilakukan agar untuk mengetahui apakah suatu perusahaan sudah bergerak di proses bisnisnya secara optimal untuk memaksimalisasikan kinerja perusahaan tersebut. Gap analysis dapat dilihat melalui beberapa perspektif, yaitu :

1. Organisasi ( Sumber daya manusia),

2. Arah bisnis perusahaan

3. Proses bisnis perusahaan

Teknologi informasi.(Hoffman \& Bateson, 2010, p. 334)

Analisa gap dapat juga diartikan sebagai perbandingan kinerja aktual dengan kinerja potensial atau yang diharapkan. Sebagai metoda, analisa gap digunakan sebagai alat evaluasi bisnis yang menitikberatkan pada kesenjangan kinerja perusahaan saat ini dengan kinerja yang sudah ditargetkan sebelumnya(Saluky, 2016).

\section{Pembahasan}

Keamanan aplikasi web melalui penerapan teknik cross site request forgery(csrf) protection, dilakukan dengan tujuan sebagai berikut:

\section{Mengetahui penggunaan metode enkripsi keamanan aplikasi web melalui teknik} cross site request forgery(csrf) protection

Penentuan metode enkripsi yang dipakai csrf-token pada aplikasi web adalah AES-256CBC. AES (Advanced Encryption Standard) menggunakan algoritma Rijndael yang telah memenangkan sayembara terbuka yang dilakukan oleh NIST (National Institute of Standard and Technology). Sayembara ini dilakukan untuk menemukan algoritma baru untuk menggantikan algoritma DES (DataEncryption Standard) yang dirasa sudah tidak aman lagi. Algoritma Rijndael menggunakan substitusi dan permutasi, dan 
sejumlah putaran (cipher berulang), setiap putaran menggunakan kunci internal yang berbeda (kunci setiap putaran disebut round key). Rijndael beroperasi dalam orientasi byte. Garis besar algoritma Rijndael yang beroperasi pada blok 256 bit dengan panjang kunci 256 bit.(Silva, Dessyanto, \& Heriyanto, 2013, p. 34)

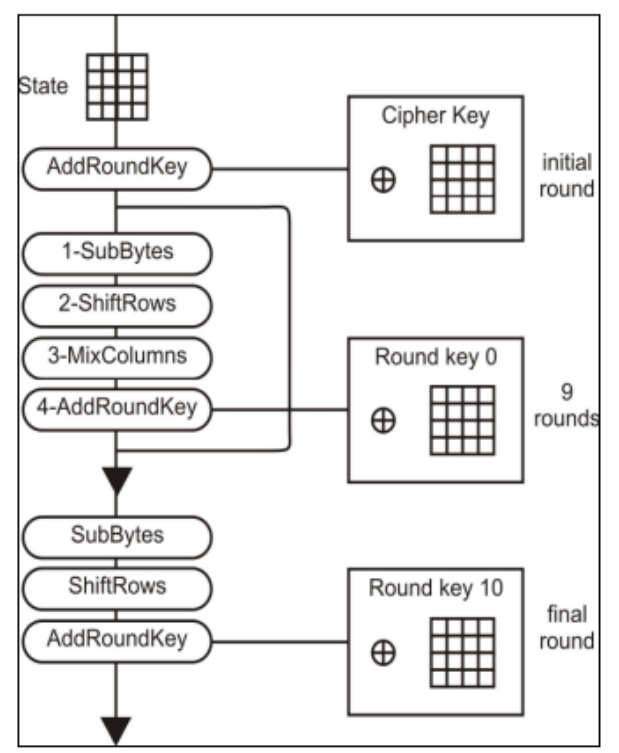

Gambar 3 Diagram Proses Enkripsi AES

\section{Merancang kunci enkripsi token keamanan aplikasi web melalui teknik cross site}

\section{request forgery(csrf) protection}

Dalam merancang kunci enkripsi yang pertama kali diperhatikan adalah panjang kunci enkripsi dan kedua adalah alpha-numeric acak agar kunci tidak dapat ditebak oleh penyerang. Panjang kunci akan digunakan pada tahap pengulangan proses enkripsi, semakin panjang kunci maka semakin aman. Pada Laravel PHP Framework disediakan sebuah fungsi yang dapat memudahkan pembuatan kunci enkripsi dengan cara sebagai berikut: 
1. Buka console atau cmd lewat start menu atau fitur run

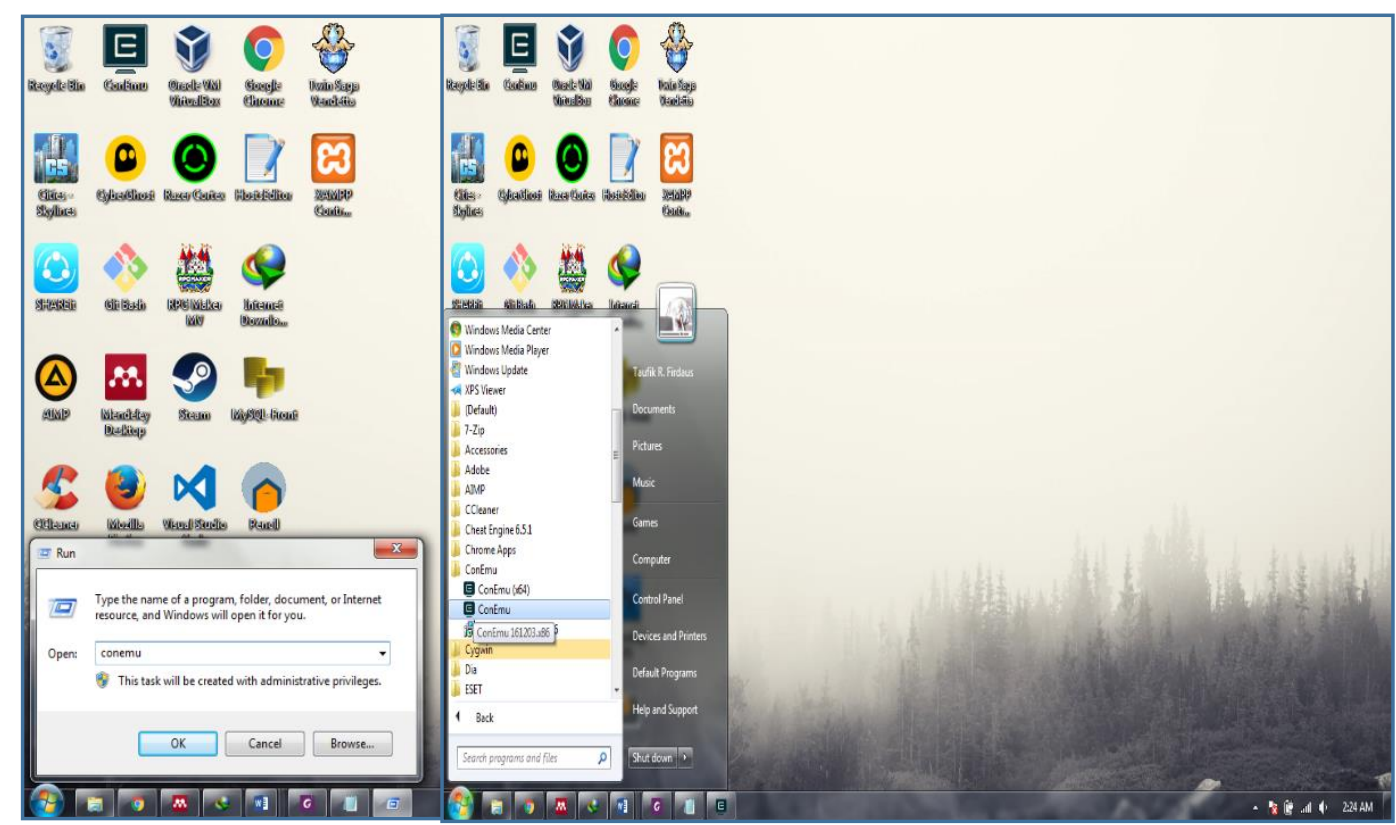

Gambar 5 Petunjuk Membuka Console Atau CMD

2. Masuk ke folder aplikasi web site yang telah dibuat dengan laravel framework dengan menggunakan perintah cd untuk melakukan pindah folder

3. Setelah berhasil masuk ke folder aplikasi web selanjutnya adalah dengan mengetikkan atau menuliskan perintah bawaan laravel framework untuk membuat kunci enkripsi yaitu php artisan key: generate

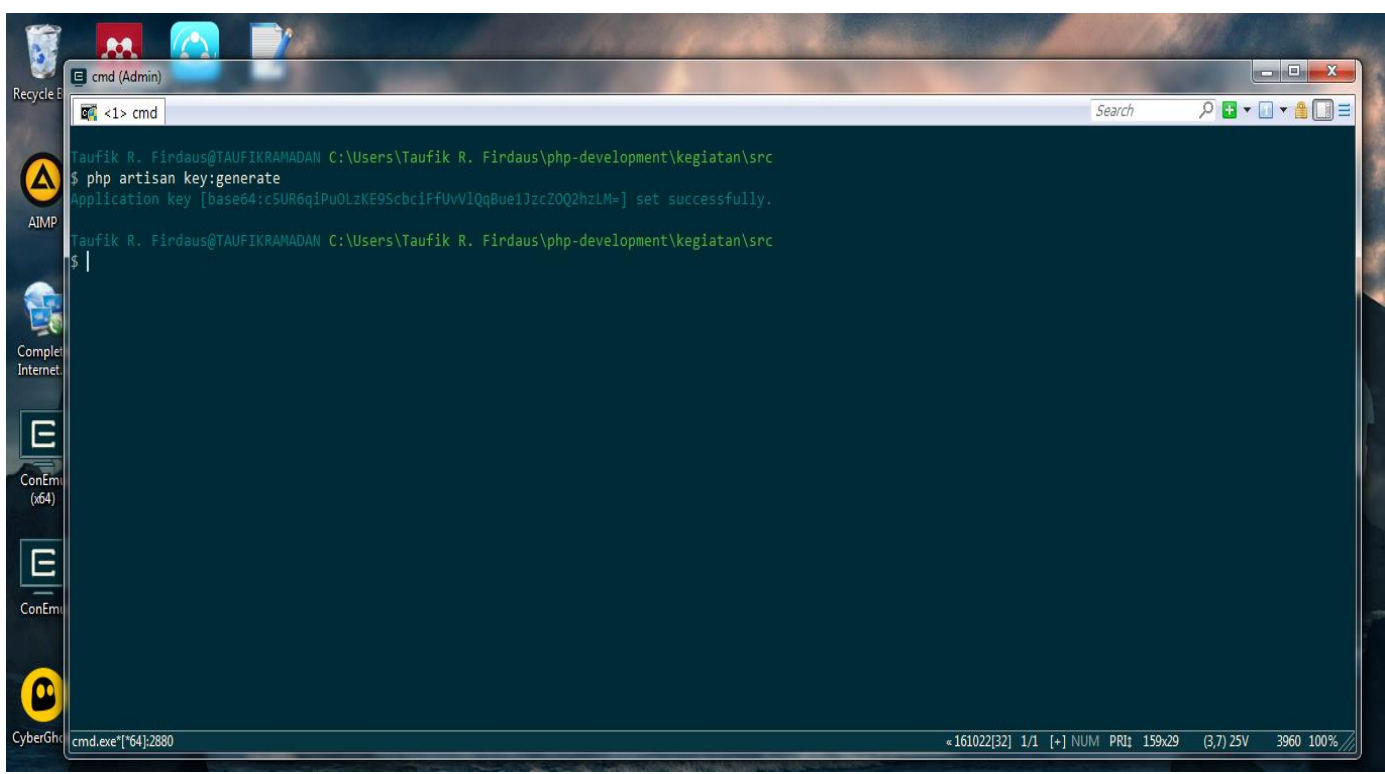

Gambar 6 Membuat Kunci Enkripsi 
4. Jika kunci enkripsi telah dibuat maka kunci yang dihasil kan akan tersimpan didalam file .env

3. Mengimplementasi keamanan aplikasi web melalui teknik cross site request forgery(csrf) protection

Langkah - langkah mengimplementasikan keamanan aplikasi web melalui teknik cross site request forgery(CSRF) protection adalah sebagai berikut:

a. Membuat diagram alir(FlowChart) proses pengamanan melalui penerapan teknik cross site request forgery(CSRF) protection

Pada tahapan ini, akan dibuat sebuah rancangan flowchat yang menggambarkan jalannya alur keamanan aplikasi web melalui penerapan teknik cross site request forgery(csrf) protection. FlowChart akan menggambarkan:

1. Proses Saat Login

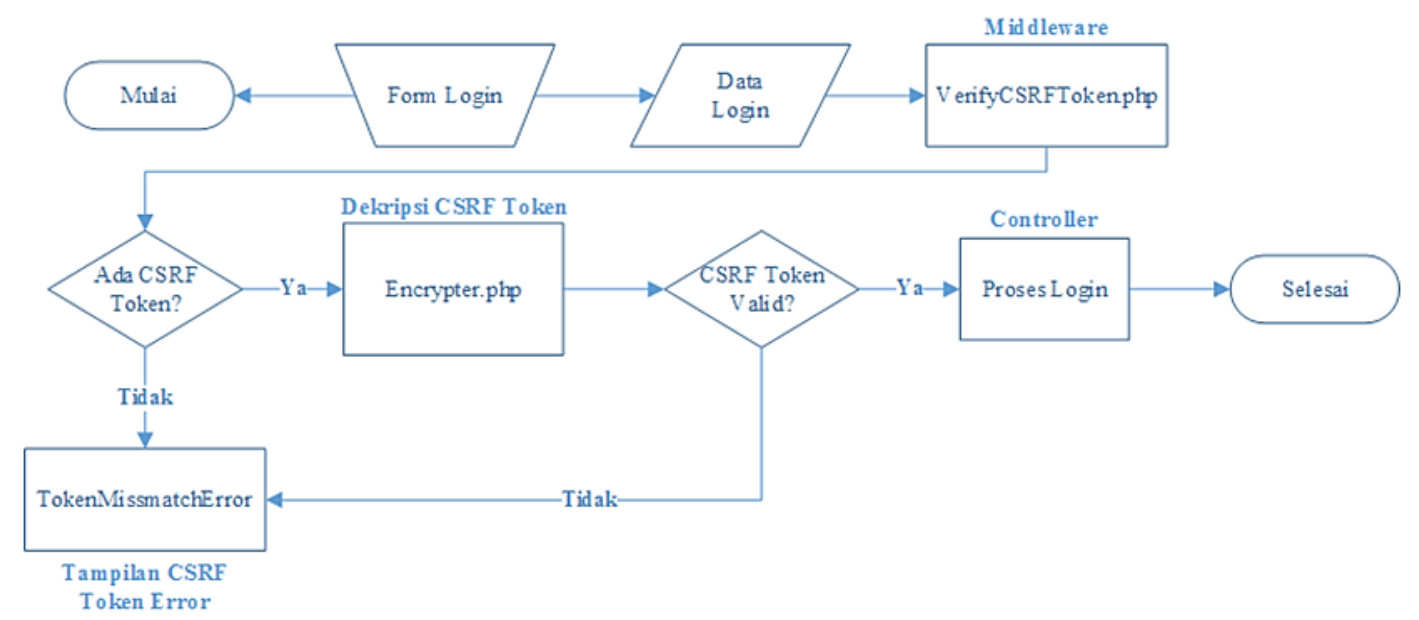

Gambar 7 Proses Pengamanan CSRF Protection Saat Login 
Mengetahui penggunaan metode enkripsi keamanan aplikasi web melalui teknik cross site request forgery(csrf) protection

Dalam hal ini hasil yang didapat dari mengetahui penggunaan metode enkripsi adalah AES256-CBC yang merupakan pengembangan terbaru metode enkripsi menggunakan algoritma Rijndael dimana enkripsi ini telah memenangkan lomba yang diselenggarakan oleh NIST (National Institute of Standard and Technology). Dimana lomba tersebut bertujuan mencari metode enkripsi terbaru yang dapat menggantikan metode enkripsi DES yang sudah tidak aman lagi. Keunggulan metode enkripsi AES-256-CBC adalah kecepatan dan keamanan dalam melakukan enkripsi teks atau pesan sehingga isi(arti) pesan tersebut tidak dapat dilihat oleh orang yang tidak memiliki kunci enkripsi tersebut.

Merancang kunci enkripsi token keamanan aplikasi web melalui teknik cross site request forgery(csrf) protection

Dalam pembuatan kunci enkripsi yang dapat dihasilkan melalui penggunaan perintah lewat command line $(\mathrm{cmd})$ dapat dilihat pada file .env yang akan digunakan setiap kali melakukan dekripsi password saat login dan disaat melakukan verifikasi csrf-token.

\section{Mengimplementasi keamanan aplikasi web melalui teknik cross site request forgery(csrf) protection}

Hasil dari implementasi keamana aplikasi web melalui teknik cross site request forgery(CSRF) protection yaitu:

a. Form yang aman dari serangan cross site request forgery(CSRF) 


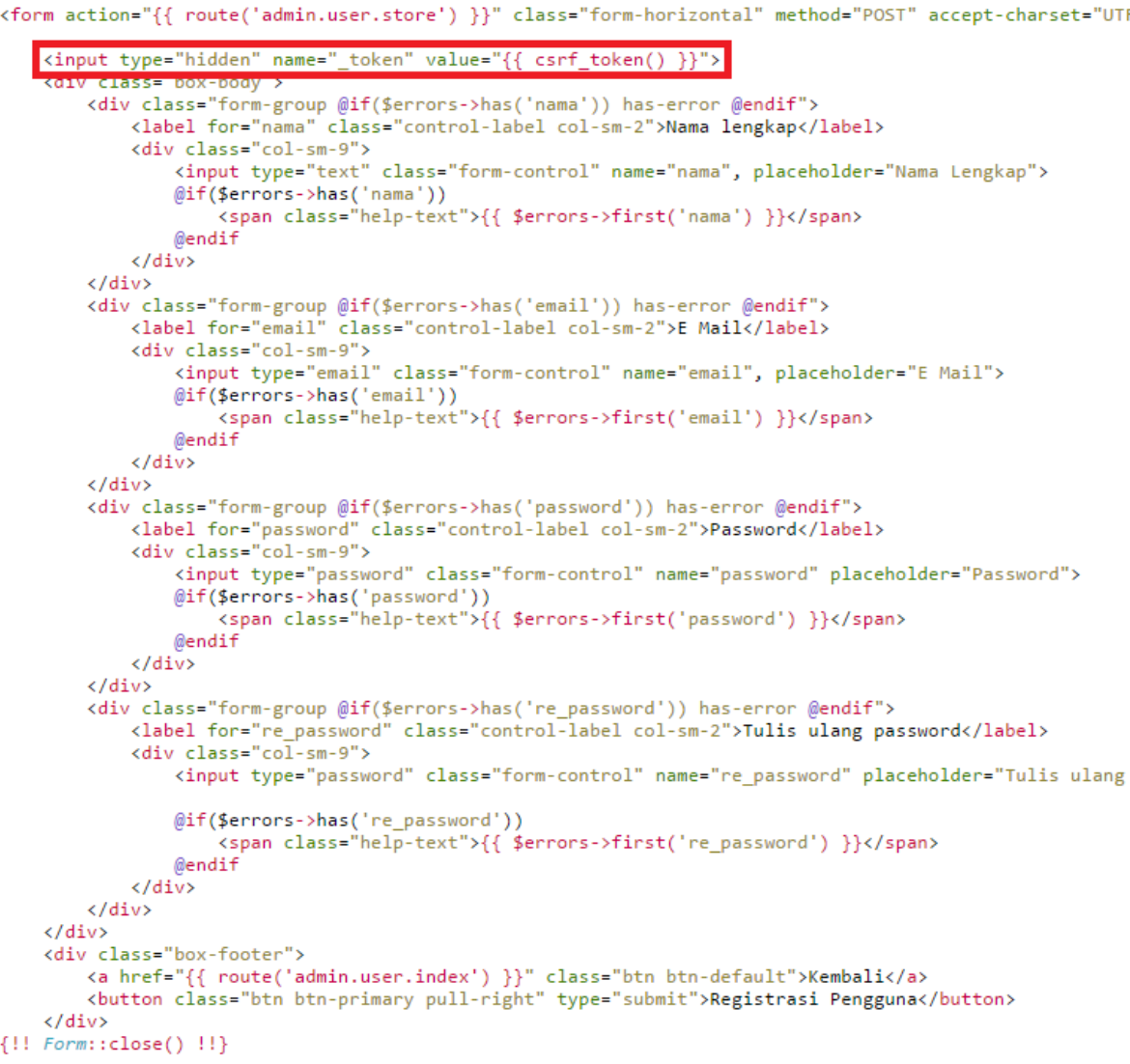

Gambar 8 Kode Program Form Login

b. CSRF-Token dan password pengguna yang tidak mudah ditebak

Keamanan aplikasi web dari serangan cross site request forgery(CSRF) tidak mudah ditebak karena csrf-token beserta password telah dienkripsi serta kunci dari enkripsi tersebut disimpan dalam file .env yang terletak didalam root folder aplikasi web.

Mengevaluasi keamanan aplikasi web melalui teknik cross site request forgery(csrf) protection

Populasi penelitian ini adalah Data Center di IAIN Syekhnurjati Cirebon, dengan sample data yang berupa kode program aplikasi web dan dianalisi menggunakan metode gap data yang dihasilkan berupa table, grafik dan gambar hasil ujicoba sebagai berikut: 
Table 1 Hasil Ujicoba Keamanan Aplikasi Web Dari Serangan CSRF

\begin{tabular}{|c|l|c|c|}
\hline \multirow{2}{*}{ No } & \multicolumn{2}{|c|}{ Nama Form } & \multicolumn{2}{|c|}{ Hasil Ujicoba Serangan CSRF } \\
\cline { 3 - 4 } & $\begin{array}{c}\text { Sebelum } \\
\text { Penerapan }\end{array}$ & $\begin{array}{c}\text { Sesudah } \\
\text { Penerapan }\end{array}$ \\
\hline 1 & Form Login & Tidak Aman & Aman \\
\hline 2 & Form Pendaftaran Pengguna & Tidak Aman & Aman \\
\hline 3 & Form Jabatan & Tidak Aman & Aman \\
\hline 4 & Form Lokasi & Tidak Aman & Aman \\
\hline 5 & Form Kegiatan & Tidak Aman & Aman \\
\hline
\end{tabular}

\section{Kesimpulan}

Dari hasil di atas dapat diambil kesimpulan bahwa Keamanan Aplikasi Web Melalui Penerapan

Teknik Cross Site Request Forgery(CSRF) Protection diantaranya:

1. Mengetahui penggunaan metode enkripsi keamanan aplikasi web melalui teknik cross site request forgery(csrf) protection

Penggunaan AES-256-CBC sebagai metode enkripsi dapat dikatakan sebagai pilihan yang tepat dikarenakan telah melalui perbandingan dengan metode enkripsi lain.

\begin{tabular}{|l|c|c|c|}
\hline \multicolumn{1}{|c|}{ Algoritma } & MiB/Second & Cycles Per Byte & $\begin{array}{c}\text { Microseconds } \\
\text { to } \\
\text { Setup Key }\end{array}$ \\
\hline SHA-256 & 111 & 15.8 & No Key \\
\hline SHA-512 & 99 & 17.7 & No Key \\
\hline RIPEMD-320 & 110 & 15.9 & No Key \\
\hline AES-CBC (256-bit key) & 80 & 21.7 & 0.619 \\
\hline AES-CBC (128-bit key) & 109 & 16.0 & 0.569 \\
\hline
\end{tabular}

Table 5.1 Tabel Perbandingan Algoritma Enkripsi

Berdasarkan table 5.1 dapat dilihat bahwa AES -CBC-256 lebih unggul dari metode enkripsi yang lain. Metode enkripsi AES-CBC-256 memiliki kecepatan enkripsi 80 MiB/Second, pengulangan enkripsi 21.7 putaran per byte, dan 0,619 microseconds untuk memasang kunci enkripsi. Dengan ini dapat dikatakan bahwa pemelihan AESCBC-256 sebagai metode enktipsi dengan tepat. 
2. Merancang kunci enkripsi token keamanan aplikasi web melalui teknik cross site request forgery(csrf) protection

Pada penrancangan kunci enkripsi diperlukan kunci yang tidak mudah ditebak, tidak sering dipakai, dan tidak pendek sehingga, kunci tidak mudah ditebak atau lolos ke tangan orang yang memiliki niat jahat pada aplikasi web.

3. Mengimplementasi keamanan aplikasi web melalui teknik cross site request forgery(csrf) protection

a. Dalam mengimplementasikannya token harus selalu diberikan pada setiap halaman dan di dalam form

b. Saat proses verifikasi, token yang disimpan dengan token yang ada pada form harus sama

c. Desain ulang table pengguna sangat dibutuhkan agar token dapat disimpan dan digunakan pada saat yang diperlukan

d. Alur diagram keamanan aplikasi web dari serangan cross site request forgery(csrf) perlu dibuat, untuk memudahkan dalam mengimplementasikan teknik keamanan

4. Mengevaluasi keamanan aplikasi web melalui teknik cross site request forgery(csrf) protection

Untuk evaluasi keamanan aplikasi web melalui teknik cross site request forgery(csrf) protection masih dibutuhkan tenaga ahli(orang) yang mengerti tentang celah keamanan aplikasi web dan cara mengamankan aplikasi web

\section{Daftar Pustaka}

Barth, A., Jackson, C., \& Mitchell, J. C. (2008). Robust defenses for cross-site request forgery. Proceedings of the 15th ACM Conference on Computer and Communications Security CCS 08, 75. http://doi.org/10.1145/1455770.1455782

Hoffman, K. D., \& Bateson, J. E. G. (2010). Services Marketing Concept, Strategies, \& Cases. 
Kombade, R. D., \& Meshram, B. B. (2012). CSRF Vulnerabilities and Defensive Techniques. International Journal of Computer Network and Information Security(IJCNIS), 4(1), 31. http://doi.org/10.5815/ijcnis.2012.01.04

Ramarao, R. (2009). HEURISTICS FOR PREVENTING CROSS SITE REQUEST FORGERY. Saluky. (2016). Pengembangan Blueprint Sistem Informasi Akademik Terintegrasi (Studi Kasus: IAIN Syekh Nurjati Cirebon). ITEj (Information Technology Engineering $\begin{array}{llll}\text { Journals }), & \text { Engineering). } & \text { Retrieved }\end{array}$ https://www.syekhnurjati.ac.id/jurnal/index.php/itej/article/view/1251

Shklar, L., \& Rosen, R. (2003). Web Application Architecture: Principles, Protocols and Practices. Software Engineering.

Silva, L. D. P., Dessyanto, B. P., \& Heriyanto. (2013). Aplikasi Enkripsi Dan Dekripsi File Dengan Menggunakan Aes (Advanced Encryption Standard) Algoritma Rijndael Pada Sistem Operasi Android. Aplikasi Enkripsi, 10(1), 33-42.

Stuttard, D., \& Pinto, M. (2011). The Web Application Hacker's Handbook: Finding and Exploiting Security Flaws (Vol. 7).

Vo, J. (n.d.). Learning Laravel : The Easiest Way.

Wells, C. (2007). Securing Ajax Applications. (Tatiana Apandi, Ed.)O'Reilly Media, Inc. (1st ed., Vol. 1). O’Reilly Media, Inc. http://doi.org/10.1017/CBO9781107415324.004 